\title{
PTK7 as a potential prognostic and predictive marker of response to adjuvant chemotherapy in breast cancer patients, and resistance to anthracycline drugs
}

\author{
This article was published in the following Dove Press journal: \\ OncoTargets and Therapy \\ 6 October 2014 \\ Number of times this article has been viewed
}

\author{
Beyhan Ataseven ${ }^{1,2}$ \\ Angela Gunesch ${ }^{2}$ \\ Wolfgang Eiermann ${ }^{3}$ \\ Ronald E Kates ${ }^{4}$ \\ Bernhard Högel ${ }^{5}$ \\ Pjotr Knyazev ${ }^{6}$ \\ Axel Ullrich ${ }^{6}$ \\ Nadia Harbeck ${ }^{4}$ \\ 'Department of Gynecology and \\ Gynecologic Oncology, Kliniken \\ Essen-Mitte, Essen, Germany; \\ ${ }^{2}$ Department of Gynecology and \\ Obstetrics, Rotkreuzklinikum Munich, \\ Munich, Germany; ${ }^{3}$ Department \\ of Gynecology and Oncology, \\ Interdisciplinary Oncology Center \\ Munich, Munich, Germany; ${ }^{4}$ Breast \\ Center, Department of Gynecology \\ and Obstetrics, Ludwig-Maximilian- \\ University Munich, Munich, \\ Germany; ${ }^{5}$ Department of Pathology, \\ Rotkreuzklinikum Munich, Munich, \\ Germany; ${ }^{6}$ Department of Molecular \\ Biology, Max-Planck-Institute of \\ Biochemistry, Martinsried, Germany
}

Correspondence: Beyhan Ataseven Department of Gynecology and Gynecologic Oncology, Kliniken EssenMitte, Evangelische Huyssens-Stiftung, Henricistrasse 92, 45I36 Essen, Germany Tel +49 20I I74 3420 I

$\mathrm{Fax}+4920$ I I74 34200

Email ataseven@gmx.net
Abstract: Biomarkers predicting resistance to particular chemotherapy regimens could play a key role in optimally individualized treatment concepts. PTK7 (protein tyrosine kinase 7) belongs to the receptor tyrosine kinase family involved in several physiological, but also malignant, cell behaviors. Recent studies in acute myeloid leukemia have associated PTK7 expression with resistance to anthracycline therapy. PTK 7 mRNA expression in primary tumor tissue (PTT) and corresponding lymph node tissue (LNT) were retrospectively measured in 117 patients with early breast cancer; PTK7 expression was available in 103 PTT and 108 LNT samples. Median age was 60 years (range, 27-87 years). At a median follow-up of 28.5 months, 6 deaths and 16 recurrences had occurred. PTK7 expression correlations with clinicopathological features were computed and PTK7 expression effects on patient outcome were analyzed in three cohorts defined by adjuvant treatment: anthracycline-based treatment, other chemotherapy regimens (including taxane or other substances), or no chemotherapy. Association of PTK7 expression with clinicopathological features was seen only for age in PTT and nodal stage in LNT. High LN PTK7 was associated with poorer disease-free survival (DFS) in the total population (3-year DFS: low [81.7\%] versus high $[70.4 \%] ; P=0.016$ ) and in patients without adjuvant chemotherapy (3-year DFS: low [91.7\%] versus high $[22.3 \%] ; P<0.001)$, but not in patients receiving adjuvant chemotherapy $(P=0.552)$. DFS stratified by PTK7 expression was compared in treatment cohorts: In patients with low LN PTK7 expression, neither chemotherapy cohort showed significantly better survival than the no-chemotherapy cohort. In patients with high LN PTK7 expression, those receiving chemotherapy, including substances other than anthracyclines, but not those receiving only anthracycline-based chemotherapy, showed significantly better DFS than those receiving no chemotherapy $(P=0.001)$. Our results support earlier findings that PTK7 may be a prognostic and predictive marker associated with resistance to anthracycline-based chemotherapy. Further investigations are needed to validate these findings in breast cancer.

Keywords: breast cancer, PTK7, protein tyrosine kinase 7, chemoresistance, prognostic factors, predictive factors

\section{Introduction}

Breast cancer (BC) is the most common malignancy for women in developed countries. During the last century, advances in screening, surgery, radiotherapy, and systemic therapy have led to high rates of local and distant disease control, resulting in survival improvement for patients with early-stage $\mathrm{BC} .{ }^{1-3}$ So far, it is accepted that $\mathrm{BC}$ is a systemic disease, with micrometastatic involvement at diagnosis in many patients. Therefore, during the last decades, systemic neoadjuvant/adjuvant therapy has been 
used to eradicate potential micrometastatic disease in early treatment of BC patients. Adjuvant systemic therapies reduce risk for relapse and death, as shown in several metaanalyses. ${ }^{4-6}$ In terms of targeted therapy, hormonal therapy in hormone receptor-positive $e^{7-9}$ and trastuzumab therapy in human epidermal growth factor receptor 2 (HER2)-positive $^{10,11}$ patients are well established. However, chemotherapy remains an important backbone in systemic treatment, especially in patients with high relapse risk. Anthracyclinebased poly-chemotherapy regimens are most widely used; the addition of taxanes into chemotherapy has improved survival benefits in the adjuvant setting. ${ }^{5}$ Unfortunately, dose limiting and long-term adverse effects, as well as resistance, represent challenges to further improvement in the efficacy of adjuvant BC chemotherapy. ${ }^{12}$ Therefore, it is very important to understand the molecular mechanism of resistance to chemotherapeutic drugs and spare the nonnegligible adverse effects for patients.

Protein tyrosine kinase 7 (PTK7), also known as colon carcinoma kinase, is an evolutionary, highly conserved cell surface planar cell polarity (PCP) receptor that belongs to the family of receptor tyrosine kinase. The PTK7 gene is located on chromosome 6 (6p21.1-p12.2), ${ }^{13}$ and it encodes a transmembrane protein containing seven immunoglobulinlike loops, a transmembrane domain, and an inactive catalytic tyrosine kinase domain. ${ }^{14,15}$ The ligand has not yet been identified. PTK7 has been shown to be highly involved in the canonical and noncanonical Wnt pathway. ${ }^{16}$ It plays a role in multiple cellular processes including tube formation, ${ }^{17}$ migration, ${ }^{18}$ and invasion of endothelial cells and angiogenesis. ${ }^{19}$ It is believed that PTK7 may affect cell clustering or cell contact persistence. Increased expression of PTK7 has been found in several human tumors, suggesting a role in human carcinogenesis. ${ }^{20-25}$ However, the prognostic effect of PTK7 expression in cancer remains unclear. In a previous study, we identified PTK7 as a potential mediator of motility and invasiveness of $\mathrm{BC}$ cells. ${ }^{26} \mathrm{~A}$ recent study indicates that PTK7 may induce resistance to anthracycline chemotherapy in human bone cancer cell lines and acute myeloid leukemia (AML) patients. ${ }^{24}$ However, the role of PTK7 in early BC in the development of acquired chemoresistance against chemotherapeutic agents, including anthracyclines, has not yet been elucidated.

The aim of our analysis was to investigate messenger RNA (mRNA) expression of PTK7 by reverse transcriptionpolymerase chain reaction (RT-PCR) in early BC, to correlate PTK7 expression with clinicopathological features, to evaluate the effect of PTK7 expression on outcome in primary BC patients, and to evaluate a possible predictive role of PTK7 expression regarding chemotherapy.

\section{Material and methods Patients and tissue collection}

From 2006 to 2010, 117 BC patients (median age at diagnosis, 60 years; range, 27-87 years; 88/117 [75.2\%] with infiltrated LN and 29/117 [24.8\%] with noninfiltrated LN) were included from the Red Cross Women's Hospital Munich, Germany. This study was approved by Ethikkommission Ludwig-Maximilians-Universität ethics committee. Patients gave informed consent for the use of biological materials and relevant clinical data. Patients receiving neoadjuvant systemic therapy and those with primary distant metastases were excluded. Stage-adapted surgery was performed on breast and axillary LN. Primary tumor tissue (PTT) and lymph node tissue (LNT) were collected and stored immediately at $-80^{\circ} \mathrm{C}$ from preparation. To ensure the histological status of harvested LN, the tissues were bisected, with half submitted for routine histology and the other half taken for examination by RT-PCR. Tumor grade; tumor, node, and metastasis classification; and histopathological tumor subtype were recorded. Hormonal receptor (estrogen receptor/progesterone receptor, immunoreactive score [IRS]) and HER2 status were assessed by immunohistochemistry and/or fluorescence in situ hybridization (all cases with HER2-HercepTest ${ }^{\mathrm{TM}}$ (Dako, Denmark) Score 2, according to American Society of Clinical Oncology/College of American Pathologists guidelines ${ }^{27}$ ). Patients were treated with radiotherapy according to current national guidelines. Clinicopathological features, type of chemotherapy, and follow-up were obtained from patient records.

Adjuvant systemic treatment was determined according to guidelines at the time of diagnosis. Of 117 patients, 69 (59\%) received chemotherapy and 75 (64.1\%) received hormonal therapy; 21 of 23 HER2-positive patients received combined chemotherapy/trastuzumab therapy; 45 patients did not receive chemotherapy because of patient preference, older age, or early disease stage. Typical chemotherapy regimens were either only anthracycline-based (doxorubicin/ cyclophosphamide [AC]/epirubicin/cyclophosphamide [EC]/ fluorouracil/doxorubicin/cyclophosphamide [FAC]/fluorouracil/epirubicin/cyclophosphamide [FEC], four to six cycles) or taxane-based (docetaxel/doxorubicin/cyclophosphamide [TAC]/fluorouracil/epirubicin/cyclophosphamide - docetaxel [FEC-Doc]/fluorouracil/epirubicin/cyclophosphamide paclitaxel [FEC-Pac], four to six cycles, or six cycles of cyclophosphamide/methotrexate/fluorouracil [CMF]). 


\section{Total RNA isolation}

Total RNA was isolated using the acid guanidine thiocyanatephenol-chloroform extraction method. ${ }^{28} \mathrm{After} \mathrm{Na-acetate} \mathrm{treat-}$ ment, the total RNA was extracted with phenol-chloroform, precipitated with isopropanol, resuspended with lysis buffer, reprecipitated with isopropanol, washed with $80 \%$ ethanol, and finally dissolved in diethyl pyrocarbonate-treated $\mathrm{H}_{2} \mathrm{O}$. The total RNA concentration was determined by absorbance measurement (260/280 nm), and the quality of total RNA was verified by $1 \%$ agarose gel electrophoresis. Only samples with no evidence of DNA contamination and RNA degradation were used for cDNA synthesis.

\section{cDNA synthesis}

cDNA synthesis was performed using $5 \mu \mathrm{g}$ total RNA in an oligo (desoxythymidine) primer mix (MWG Biotech, Ebersberg, Germany; total volume, $10 \mu \mathrm{L}$ ), which was heated at $70^{\circ} \mathrm{C}$ for 3 minutes and then cooled on ice. A master mix containing $1 \times$ reverse transcriptase buffer, $1 \mathrm{mmol} / \mathrm{L}$ deoxynucleotide triphosphates, $10 \mathrm{mmol} / \mathrm{L}$ dithiothreitol (DTT), $40 \mathrm{U}$ RNase inhibitor ( $40 \mathrm{U} / \mu \mathrm{L}$; Fermentas), and $50 \mathrm{U}$ avian myeloblastosis virus reverse transcriptase $(25 \mathrm{U} / \mu \mathrm{L}$; Molecular Diagnostics, Roche) was added and subsequently incubated at $42^{\circ} \mathrm{C}$ for 2 hours. A stop reaction was performed with $80 \mu \mathrm{L}$ Tris-ethylenediaminetetraacetic acid 10/0.1, followed by heating at $72^{\circ} \mathrm{C}$ for 7 minutes. The quality of the cDNA was verified using $1.5 \%$ agarose gel electrophoresis. Afterward, the cDNA probe was denatured with $10 \mu \mathrm{L}$ and $1 \mathrm{~N} \mathrm{NaOH}, \mathrm{pH}$ neutralized with $5 \mu \mathrm{L} 2 \mathrm{~N} \mathrm{HCl}$ and $5 \mu \mathrm{L} 2 \mathrm{~N}$ Tris- $\mathrm{HCl}(\mathrm{pH}, 7.5)$, and purified using the QIAquick PCR Purification kit (Quiagen, Hilden, Germany) according to the manufacturer's instructions.

\section{RT-PCR}

The PCR method was used to determine mRNA expression levels of PTK7 and $\alpha$-tubulin (housekeeping gene) in fresh-frozen PTT and LNT samples. The following primer sequences were applied: PTK7-ex 7fwd, 5'-GGA AGC CAC ACT TCA CCT AGC AG-3', PTK7-ex11rev, 5'-CTG CCA CAG TGA GCT GGA CAT GG-3', $\alpha$-TUB fwd, $5^{\prime}$-AAG TGA CAA GAC CAT TGG GGG AGG-3', $\alpha$-TUB rev, $5^{\prime}$ GGG CAT AGT TAT TGG CAG CAT-3'. All primers were synthesized by MWG Biotech. PCR was performed using $1 \mu \mathrm{L}$ cDNA as a template in a master mix containing $1 \times \mathrm{PCR}$ buffer, $1 \mathrm{mmol} / \mathrm{L}$ deoxynucleotide triphosphates, $1 \mathrm{pmol} /$ $\mu \mathrm{L}$ of each specific primer, and 2.5 U Taq DNA polymerase (Sigma, Taufkirchen, Germany) for each sample and carried out in a thermal cycler (Eppendorf AG, Wessling-Berzdorf, Germany). PCR cycling conditions began with an initial DNA denaturation step at $94^{\circ} \mathrm{C}$ for 2 minutes, followed by 32 cycles with denaturation at $94^{\circ} \mathrm{C}$ for 30 seconds, primer annealing at the appropriate annealing temperature for 30 seconds, and extension at $72^{\circ} \mathrm{C}$ for 1 minute, followed by a final extension step at $72^{\circ} \mathrm{C}$ for 5 minutes. The amplified PCR products were analyzed by separation in a $2 \%$ agarose gel at $80 \mathrm{~V}$ for 30 minutes. The mRNA expression of the PCR products, with a size of approximately $100 \mathrm{bp}$ to $1 \mathrm{kbp}$, was evaluated semiquantitatively, using Aida Image Software (Raytest, Straubenhardt, Germany).

\section{Statistical analysis}

Two-sample $t$-tests, one-way analysis of variance, or the Mann-Whitney $U$ test were performed to test for associations between continuous and grouped variables; chi-square tests or Fisher's exact test were performed to evaluate associations between grouped variables.

Disease-free survival (DFS) and overall survival (OS) were defined in months from time of surgery. DFS end points were recurrent tumor and distant metastasis or death from BC. Survival estimates were obtained by the Kaplan-Meier method; the log-rank test was used to analyze for group differences. A binary PTK7 expression variable (high versus low) was defined using median expression as a cutoff. All reported $P$-values are two-tailed, with a nominal significance level of 5\%. Statistical analysis was performed using SPSS (version 20, IBM Corporation, New York, NY, USA).

\section{Results \\ Patient characteristics and outcome}

PTK7 mRNA expression in PTT and corresponding LNT were retrospectively measured in 117 early $\mathrm{BC}$ patients. Median age at diagnosis was 60 years (range, 27-87 years). At a median follow-up period of 28.5 months, there were 16 recurrences (13 distant, 3 local) and 6 deaths. For analysis, we defined cohort A as patients receiving exclusively anthracycline-based chemotherapy, cohort B as those receiving chemotherapy including agents other than anthracyclines (eg, taxane-based and others), and cohort $\mathrm{C}$ as patients receiving no chemotherapy. Table 1 describes and compares key parameters by cohort: Patients receiving no chemotherapy (cohort C) were older (median age, 72 years) than in cohorts A and B ( 60 and 49 years, respectively). Significant differences among the three cohorts occurred in nodal status, histological type, and HER2 status. Neither in paired comparisons among the three treatment cohorts nor in comparisons of chemotherapy versus no chemotherapy ( $P=0.340$; Figure $1 \mathrm{~A})$ were significant differences in DFS or OS observed. 
Table I Comparing cohorts A through C

\begin{tabular}{|c|c|c|c|c|}
\hline & $\begin{array}{l}\text { Cohort A, exclusively } \\
\text { anthracycline-based } \\
(n=19)\end{array}$ & $\begin{array}{l}\text { Cohort B, } \\
\text { taxane-based/ } \\
\text { others }(n=50)\end{array}$ & $\begin{array}{l}\text { Cohort C, no } \\
\text { chemotherapy } \\
(n=45)\end{array}$ & $\begin{array}{l}\text { Statistics, } \\
P \text {-value }\end{array}$ \\
\hline \multicolumn{5}{|l|}{ Parameter } \\
\hline Median age in years, range & $60(44-73)$ & $49(27-75)$ & $72(36-87)$ & $<0.001$ \\
\hline Size, pT (tumor stage) & & & & 0.241 \\
\hline pTI & $7(36.8 \%)$ & $17(34.0 \%)$ & $16(35.5 \%)$ & \\
\hline pT2 & $9(47.4 \%)$ & $28(56.0 \%)$ & $20(44.4 \%)$ & \\
\hline $\mathrm{pT} 3$ & $2(20.0 \%)$ & $5(10.0 \%)$ & $3(6.7 \%)$ & \\
\hline pT4 & I (14.3\%) & $0(0 \%)$ & $6(13.3 \%)$ & \\
\hline Histological type & & & & 0.017 \\
\hline Invasive ductal & $16(84.2 \%)$ & 45 (90.0\%) & 32 (7I.1\%) & \\
\hline Invasive lobular & $3(15.8 \%)$ & $\mathrm{I}(2.0 \%)$ & II (24.4\%) & \\
\hline Other & $2(4.4 \%)$ & $4(8.0 \%)$ & $2(33.3 \%)$ & \\
\hline Pathologic nodal status ( $\mathrm{pN}$ ) & & & & 0.001 \\
\hline $\mathrm{pNO}$ & $2(42.2 \%)$ & $8(16.0 \%)$ & 19 (42.2\%) & \\
\hline $\mathrm{pNI}$ & $6(13.3 \%)$ & $27(54.0 \%)$ & $6(13.3 \%)$ & \\
\hline $\mathrm{pN} 2$ & II (24.4\%) & $10(20.0 \%)$ & II (24.4\%) & \\
\hline $\mathrm{pN} 3$ & $9(20.0 \%)$ & $5(10.0 \%)$ & $9(20.0 \%)$ & \\
\hline Pathologic grade & & & & 0.619 \\
\hline GI & $0(0 \%)$ & $4(8.0 \%)$ & $5(11.1 \%)$ & \\
\hline $\mathrm{G} 2$ & II (57.9\%) & $30(60.0 \%)$ & $26(57.8 \%)$ & \\
\hline G3 & $8(42.1 \%)$ & $16(32.0 \%)$ & $14(31.1 \%)$ & \\
\hline Estrogen receptor status & & & & 0.245 \\
\hline Estrogen receptor positive & $13(68.4 \%)$ & $36(72.0 \%)$ & $38(84.4 \%)$ & \\
\hline Estrogen receptor negative & $6(31.6 \%)$ & $14(28.0 \%)$ & $7(15.6 \%)$ & \\
\hline Human epidermal growth factor receptor 2 status & & & & $<0.001$ \\
\hline Human epidermal growth factor receptor 2 negative & $18(94.7 \%)$ & $30(61.2 \%)$ & $4 \mathrm{I}(93.2 \%)$ & \\
\hline Human epidermal growth factor receptor 2 positive & $\mathrm{I}(5.3 \%)$ & $19(38.8 \%)$ & $3(6.8 \%)$ & \\
\hline
\end{tabular}

Notes: Cohort A, patients receiving exclusively anthracycline-based chemotherapy. Cohort B, patients receiving chemotherapy including agents other than anthracyclines (eg, taxane-based and others). Cohort C, patients receiving no chemotherapy.

\section{PTK7 expression and association with clinicopathological features}

PTK7 expression in PTT was distributed as follows: 1.72 (25th percentile), 3.04 (median), and 4.39 (75th percentile). PTK7 expression in LNT was distributed as follows: 0.58 (25th percentile), 1.68 (median), and 3.15 (75th percentile).

A moderate correlation of PTK7 levels in PTT and LNT was seen (Spearman-Rho, 0.432; $P<0.001$ ). The following associations of PTK7 expression in PTT and LNT with clinicopathological features (age; grade; tumor, node, and metastasis category; steroid hormonal receptor; and HER2 status) were seen (Table 2). High PTK7 expression in PTT occurred more frequently in younger patients; high PTK7 expression in LNT was significantly associated with higher pathologic nodal status. As a rough measure of association, LNT PTK7 level (but not PTT PTK7 level) treated as a continuous variable was correlated with nodal status (Spearman-Rho, 0.537; $P<0.001$ ).

\section{Prognostic effect of PTK7 expression}

The effects of PTK7 expression in PTT and in LNT on DFS and OS were first analyzed for the collective as a whole.
Although PTT PTK7 expression had no significant prognostic effect on DFS or OS, patients with low PTK7 expression in LNT had significantly better DFS than those with high PTK7 ( $P=0.016$; 3-year DFS: low versus high, $81.7 \%$ versus $70.4 \%$ ). In univariate Cox regression, high LNT PTK7 expression was associated with a hazard ratio of 3.76 (95\% CI: 1.19 - 11.9). LNT PTK7 expression had no significant effect on OS.

\section{PTK7 expression and chemotherapy benefit prediction}

In view of the prognostic effect of PTK7 expression in LNT, but not PTT, we consider LNT PTK7 expression in the following predictive analysis.

The effect of PTK7 expression on DFS differed according to whether chemotherapy was administered at all. As illustrated in Figure 1B, patients in cohort C with high LNT PTK7 expression $(n=14)$ showed significantly poorer DFS than those with low expression ( $\mathrm{n}=21$; 3-year DFS: $22.3 \%$ versus $91.7 \% ; P>0.001$ ); a corresponding difference was not seen in patients with chemotherapy (Figure 1C). These findings suggest a particular benefit from chemotherapy for patients with high LNT PTK7 expression. 

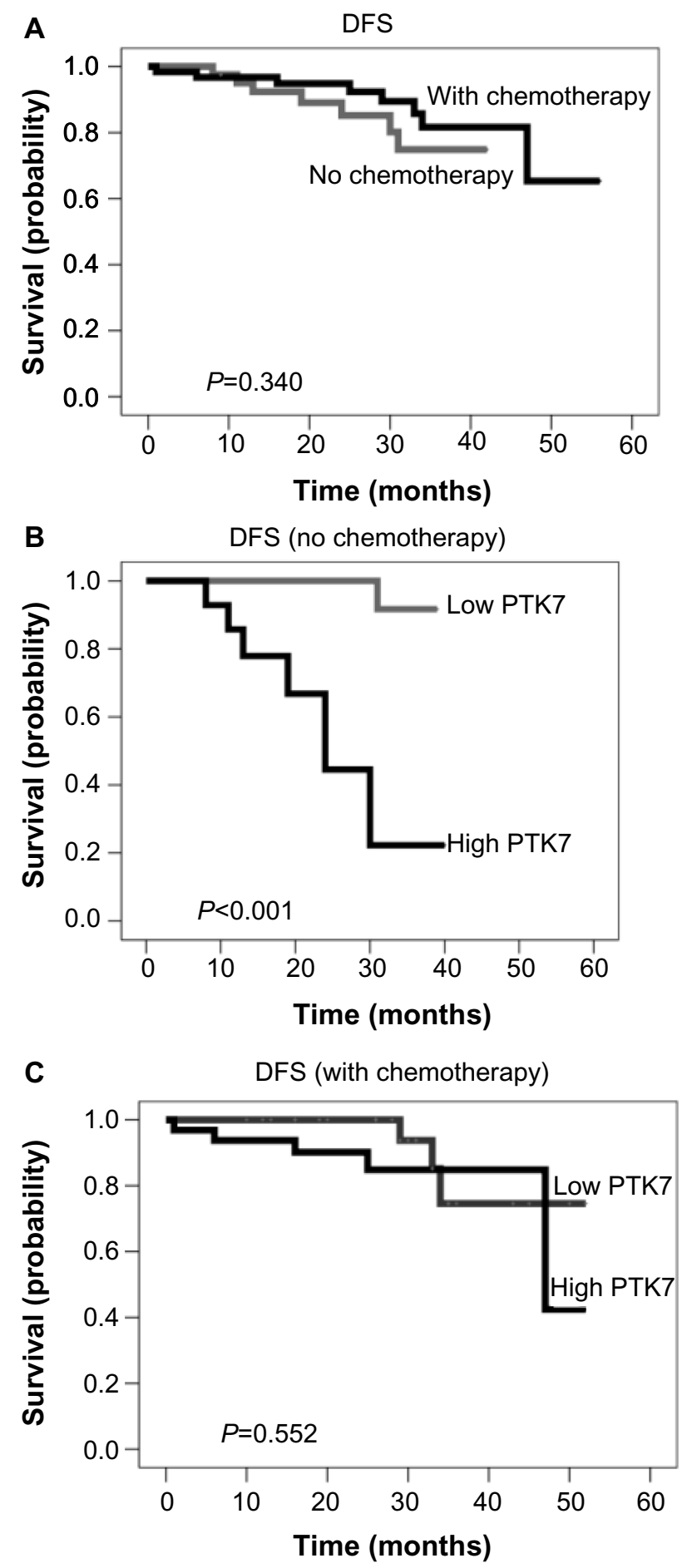

Figure I Kaplan-Meier curves for disease-free survival (DFS). (A) DFS in patients with and without adjuvant chemotherapy. (B) DFS in patients without adjuvant chemotherapy based on PTK7 expression. (C) DFS in patients with adjuvant chemotherapy based on PTK7 expression.

Taking into account the statistical power available, the hypothesis of an association of PTK7 with anthracycline resistance was investigated by evaluating the effect of PTK7 expression on DFS in the treatment cohorts defined earlier. For patients with low LNT PTK7 expression, DFS differences in $\mathrm{A}$ versus $\mathrm{C}$ and in $\mathrm{B}$ versus $\mathrm{C}$ were not significant
(Figure 2A and B). In patients with high PTK7 expression, the difference between cohort $\mathrm{A}$ and cohort $\mathrm{C}$ was borderline significant $(P=0.060$; Figure $2 \mathrm{C})$, whereas a significant difference between cohorts $\mathrm{B}$ and $\mathrm{C}$ was observed (3-year DFS: $95.2 \%$ versus $20.8 \%$; $P=0.001$; Figure 2D).

Chemotherapy selection could have been affected by differences in clinicopathological variables (Table 1; eg, more high-risk patients in cohort B). However, in multivariate analysis, hormone receptor status or histological type did not enter the models, so the large difference between cohorts B and $\mathrm{C}$ persisted in high-PTK7 patients.

\section{Discussion}

The current study of patients with primary BC is the first to investigate associations of PTK7 mRNA expression in both PTT and axillary LNT with clinicopathological parameters, as well as the effect of PTK7 mRNA expression on survival according to adjuvant chemotherapy subcohorts.

PTK7 is thought to play an important role in migration, invasion, angiogenesis, cell proliferation, and cell apoptosis. ${ }^{19,29}$ In previous work, we showed that PTK7 is able to transform NIH3T3 cells and is a potential mediator of motility and invasiveness of $\mathrm{BC}$ cells. ${ }^{26}$ Furthermore, we demonstrated that inhibition of endogenous PTK7 signaling in highly invasive $\mathrm{BC}$ cells by a dominant negative mutation or by siRNA silencing results in loss of capacity to invade the surrounding matrix and to migrate into the wound area. Our clinical data are consistent with this biological role, suggesting that the more PTK7 is expressed, the more aggressive the tumor cells are and the more they tend to migrate to the next destination (from PTT to LNT and from LNT to distant metastasis). PTK7 is upregulated in many human cancers (eg, lung cancer, ${ }^{20}$ gastric cancer, ${ }^{22}$ colon cancer, ${ }^{23,25} \mathrm{AML},{ }^{24}$ and liposarcoma ${ }^{21}$ ); however, the prognostic significance of higher PTK 7 expression may depend on cancer entity. In gastric cancer, for example, higher PTK7 expression has been linked to improved survival, whereas AML or liposarcoma patients with high tumor PTK7 had poorer outcomes.

This study detected a significant positive correlation between PTK7 expression in PTT and LNT, as well as a positive correlation between PTK7 expression level and nodal involvement (ie, tumor load). High LNT PTK7 expression was associated with substantially poorer DFS in the whole collective, with a hazard ratio of 3.76 .

PTK7 expression is thought to be associated with resistance to anthracycline chemotherapy. ${ }^{24}$ To investigate this question, our study has focused on survival, taking LNT PTK7 status and type of chemotherapy into account. PTK7 expression in LNT was associated with poorer DFS in 
Table 2 Clinical parameters of patients with primary breast cancer tissue (PTT) and lymph node tissue (LNT) displaying low or high PTK7 expression (binary variable)

\begin{tabular}{|c|c|c|c|c|c|c|c|c|}
\hline & \multicolumn{4}{|c|}{ PTK7 expression in PTT } & \multicolumn{4}{|c|}{ PTK7 expression in LNT } \\
\hline & Total & Low & High & $P$-value & Total & Low & High & $P$-value \\
\hline Age, years & & & & & & & & 1.000 \\
\hline$\leq 50$ & 40 & 17 (42.5\%) & $23(57.5 \%)$ & & 40 & $20(50.0 \%)$ & $20(50.0 \%)$ & \\
\hline$>50$ & 77 & $49(63.6 \%)$ & $28(36.4 \%)$ & 0.033 & 68 & $34(50.0 \%)$ & $34(50.0 \%)$ & \\
\hline Tumor size & & & & & & & & 0.640 \\
\hline pTI & 40 & $21(52.5 \%)$ & 19 (47.5\%) & & 36 & $21(58.3 \%)$ & 15 (4I.7\%) & \\
\hline pT2 & 59 & $34(57.6 \%)$ & 25 (42.4\%) & & 56 & $26(46.4 \%)$ & $30(53.6 \%)$ & \\
\hline PT3 & 11 & 7 (63.6\%) & $4(36.4 \%)$ & & 10 & $4(40.0 \%)$ & $6(60.00 \%)$ & \\
\hline $\mathrm{pT} 4$ & 7 & $4(57.1 \%)$ & $3(42.9 \%)$ & 0.915 & 6 & $3(50.0 \%)$ & $3(50.0 \%)$ & \\
\hline Histological type & & & & & & & & 0.360 \\
\hline Invasive ductal & 96 & $51(53.1 \%)$ & 45 (46.9\%) & & 90 & 44 (48.9\%) & $46(51.1 \%)$ & \\
\hline Invasive lobular & 15 & II (73.3\%) & $4(26.7 \%)$ & & 12 & $8(66.7 \%)$ & $4(33.3 \%)$ & \\
\hline Other & 6 & $4(66.7 \%)$ & $2(33.3 \%)$ & 0.297 & 6 & $2(33.3 \%)$ & $4(66.7 \%)$ & \\
\hline Lymph node status & & & & & & & & $<0.001$ \\
\hline No & 29 & 18 (62.1\%) & II (37.9\%) & & 28 & 20 (7I.4\%) & $8(28.6 \%)$ & \\
\hline NI & 44 & $23(52.3 \%)$ & $21(47.7 \%)$ & & 41 & $25(61.0 \%)$ & $16(39.0 \%)$ & \\
\hline N2 & 27 & $14(51.9 \%)$ & $13(48.1 \%)$ & & 23 & $8(34.8 \%)$ & $15(65.2 \%)$ & \\
\hline N3 & 17 & II (64.7\%) & $6(35.3 \%)$ & 0.708 & 16 & I (6.2\%) & 15 (93.8\%) & \\
\hline Estrogen receptor status & & & & & & & & 0.067 \\
\hline Positive & 90 & $52(57.8 \%)$ & 38 (42.2\%) & & 83 & $46(55.4 \%)$ & 37 (44.6\%) & \\
\hline Negative & 27 & $14(51.9 \%)$ & $13(48.1 \%)$ & 0.660 & 25 & $8(32.0 \%)$ & $17(68.0 \%)$ & \\
\hline $\begin{array}{l}\text { Human epidermal growth } \\
\text { factor receptor } 2\end{array}$ & & & & & & & & 0.058 \\
\hline Negative & 92 & $56(60.9 \%)$ & 36 (39.1\%) & & 83 & $46(55.4 \%)$ & 37 (44.6\%) & \\
\hline Positive & 23 & $10(43.5 \%)$ & $13(56.5 \%)$ & 0.160 & 23 & $7(30.4 \%)$ & $16(69.6 \%)$ & \\
\hline Histological grading & & & & & & & & 0.479 \\
\hline GI & 9 & $5(55.6 \%)$ & $4(44.4 \%)$ & & 9 & $6(66.7 \%)$ & 3 (33.3\%) & \\
\hline $\mathrm{G} 2$ & 70 & $4 \mathrm{l}(58.6 \%)$ & 29 (4I.4\%) & & 65 & $33(50.8 \%)$ & 32 (49.2\%) & \\
\hline G3 & 38 & $20(52.6 \%)$ & 18 (47.4\%) & 0.837 & 34 & 15 (44. I\%) & 19 (55.9\%) & \\
\hline Chemotherapy type & & & & & & & & 0.348 \\
\hline Cohort A & 19 & 12 (63.2\%) & 7 (36.8\%) & & 17 & $6(35.3 \%)$ & II (64.7\%) & \\
\hline Cohort B & 50 & $25(50.5 \%)$ & 25 (50.0\%) & & 50 & $25(50.0 \%)$ & $25(50.0 \%)$ & \\
\hline Cohort C & 45 & $26(57.8 \%)$ & $19(36.8 \%)$ & $0.56 \mathrm{I}$ & 39 & $22(56.4 \%)$ & 17 (43.6\%) & \\
\hline
\end{tabular}

Notes: Cohort A: patients receiving exclusively anthracycline-based chemotherapy. Cohort B: patients receiving chemotherapy, including agents other than anthracyclines (eg, taxane-based and others). Cohort C: patients receiving no chemotherapy.

patients receiving no chemotherapy, but not in those receiving chemotherapy.

In our collective, high LNT PTK7 expression was associated with a significantly poorer DFS in patients receiving no chemotherapy, but not in those receiving chemotherapy.

In patients with high LNT PTK7 expression (but not in those with low LNT PTK7 expression), DFS in cohort A (anthracyclines only) was not significantly better than in the no-chemotherapy cohort (C) but was much better in cohort $\mathrm{B}$ (chemotherapy not limited to anthracyclines) than in cohort C. Taken together, these results are consistent with previous findings in AML, suggesting an association between high PTK7 and anthracycline resistance and with the interpretation that chemotherapy regimens including agents other than anthracyclines are particularly effective in high-PTK7 patients. In a recent article, ${ }^{30}$ we evaluated the effect of PTK7 expression measured by immunohistochemistry in triplenegative $\mathrm{BC}$ and observed a (nonsignificant) trend toward poorer survival of patients with PTK7-positive tumors treated with anthracycline-based chemotherapy (ie, consistent with the hypothesis of drug resistance).

To date, little progress has been made in the field of predictive biomarkers for chemotherapy benefit in BC. As a consequence, a vast majority of patients considered to be at moderate or high risk for relapse are treated with those cytotoxic agents viewed as the most active; namely, anthracyclines and taxanes, both of which are associated with significant adverse effects. Unfortunately, resistance remains a significant drawback to clinical success in chemotherapy, as in other 

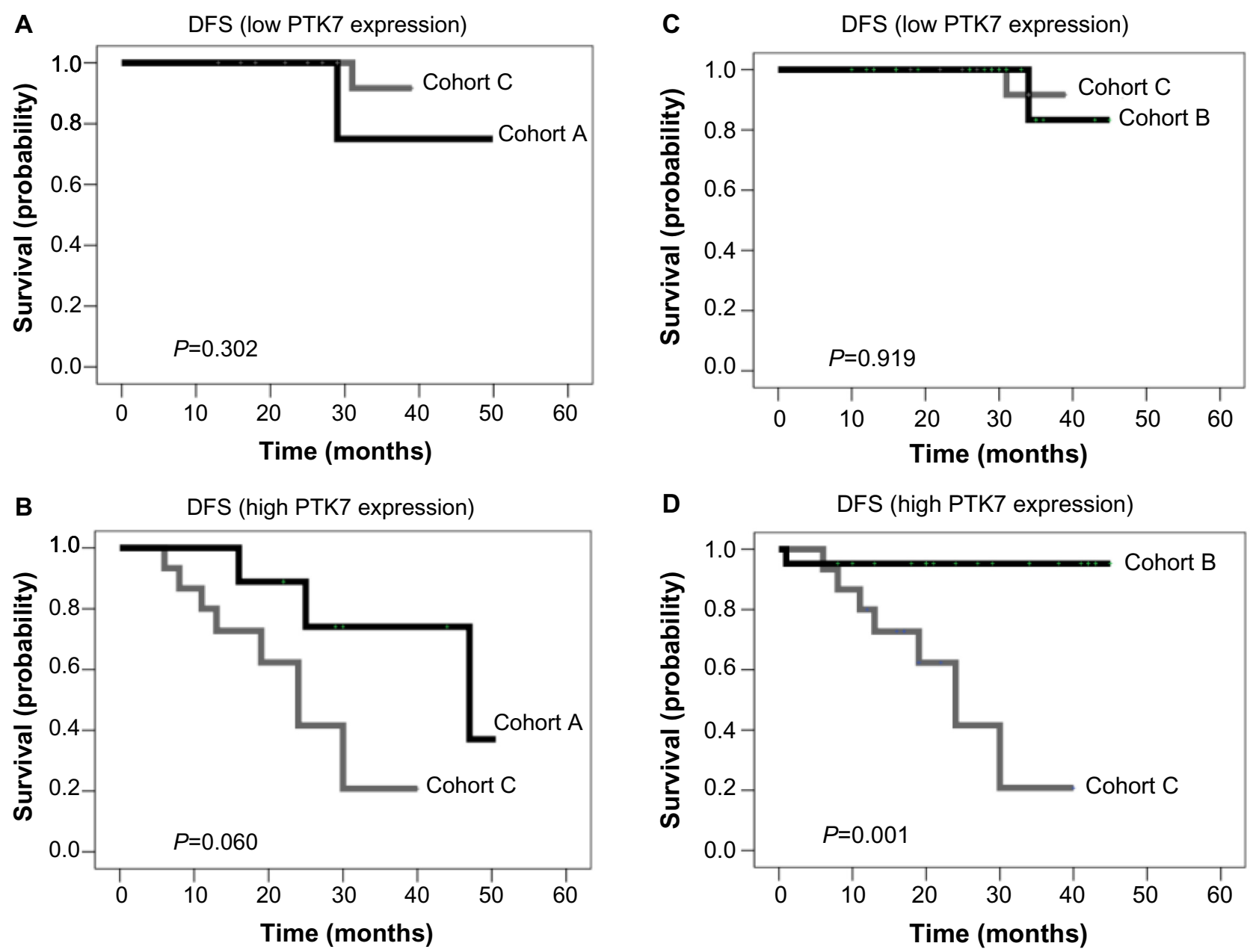

Figure 2 Kaplan-Meier curves for disease-free survival (DFS) distributed in therapy cohorts and protein tyrosine kinase (PTK) expression. (A) DFS in patients with low PTK7 expression treated with only anthracycline-based chemotherapy (cohort A) versus no chemotherapy (cohort C). (B) DFS in patients with high PTK7 expression treated with only anthracycline-based chemotherapy (cohort A) versus no chemotherapy (cohort C). (C) DFS in patients with low PTK7 expression treated with taxane-based/other chemotherapy (cohort B) versus no chemotherapy (cohort C). (D) DFS in patients with high PTK7 expression treated with taxane-based/other chemotherapy (cohort B) versus no chemotherapy (cohort C).

systemic therapy concepts. Therefore, identification of new markers with a predictive value regarding chemotherapy response can play a key role in the development of individualized treatment strategies to further improve efficacy and minimize adverse effects.

Conclusive recommendations from the current study are not yet possible because of weaknesses such as a nonstandardized detection assay, retrospective trial design, nonrandomized treatment groups, and limited sample size. In particular, the results should not be interpreted as a recommendation on which patients should receive adjuvant chemotherapy or a particular kind of chemotherapy. However, the results are certainly hypothesis-generating and warrant validation in a larger BC collective, particularly in view of the independent biological and medical evidence for a predictive role of PTK7 in chemotherapy response, and particularly in anthracycline resistance.

\section{Conclusion}

To the best of our knowledge, this is the first report using RT-PCR for investigating the relationship between PTK7 expression and outcome in $\mathrm{BC}$ specifically looking at anthracycline-based chemotherapy. High PTK7 expression in LNT is associated with high tumor load and with poorer DFS in patients with no chemotherapy or only-anthracyclinebased adjuvant chemotherapy, but not in patients treated by taxane-based chemotherapy. Provided these findings can be independently validated, PTK7 may be an important prognostic and predictive biomarker. Further strategies for targeting PTK7 may thus offer novel therapeutic opportunities in $\mathrm{BC}$ treatments.

\section{Acknowledgments}

We thank all patients for participating in this trial and donating their cancer tissue. We are grateful for the active 
support of Tatiana Knyazeva and Silvia Gärtner. The work was funded by the Max Planck Society. Statistical analysis (REK) was supported by a grant from the University of Munich (to NH).

\section{Author contributions}

BA provided the concept and design; recruited patients and collected tissue; provided experimental and data analysis and interpretation, critical revision, and final approval; and wrote the first draft of the manuscript and provided comments. AG provided experimental and data analysis and interpretation, critical revision, and final approval and reviewed the draft and provided comments. WE provided the concept and design, recruited patients and collected tissue, and performed experimental and data analysis and interpretation, as well as critical revision, and provided comments. REK provided statistical analysis, data analysis and interpretation, critical revision, and review and comments on manuscript development, as well as final approval. BH provided experimental and data analysis and interpretation, critical revision, reviewed the draft, and provided comments. PK provided concept and design, experimental and data analysis and interpretation, critical revision, and final approval and reviewed the draft and provided comments. AU provided experimental and data analysis and interpretation, critical revision and final approval and reviewed the draft and provided comments. NH provided data analysis and interpretation and critical revision, reviewed and provided comments on manuscript development, and provided final approval.

\section{Disclosure}

PK and AU are listed as inventors on the European Patent Application no 10075169.2, "PTK-7 Protein Involved in Breast Cancer." The other authors report no conflicts of interest in this work.

\section{References}

1. Peto R, Davies C, Godwin J, et al; Early Breast Cancer Trialists' Collaborative Group (EBCTCG). Comparisons between different polychemotherapy regimens for early breast cancer: meta-analyses of long-term outcome among 100,000 women in 123 randomised trials. Lancet. 2012;379(9814):432-444.

2. Darby S, McGale P, Correa C, et al; Early Breast Cancer Trialists' Collaborative Group (EBCTCG). Effect of radiotherapy after breastconserving surgery on 10-year recurrence and 15 -year breast cancer death: meta-analysis of individual patient data for 10,801 women in 17 randomised trials. Lancet. 2011;378(9804):1707-1716.

3. Davies C, Godwin J, Gray R, et al; Early Breast Cancer Trialists' Collaborative Group (EBCTCG). Relevance of breast cancer hormone receptors and other factors to the efficacy of adjuvant tamoxifen: patientlevel meta-analysis of randomised trials. Lancet. 2011;378(9793): 771-784.
4. Ginés J, Sabater E, Martorell C, Grau M, Monroy M, Casado MA. Efficacy of taxanes as adjuvant treatment of breast cancer: a review and meta-analysis of randomised clinical trials. Clin Transl Oncol. 2011;13(7):485-498.

5. Palmieri C, Jones A. The 2011 EBCTCG polychemotherapy overview. Lancet. 2012;379(9814):390-392.

6. Qin Y-Y, Li H, Guo X-J, et al. Adjuvant chemotherapy, with or without taxanes, in early or operable breast cancer: a meta-analysis of 19 randomized trials with 30698 patients. PLoS ONE. 2011;6(11):e26946.

7. Cuzick J, Sestak I, Baum M, et al; ATAC/LATTE investigators. Effect of anastrozole and tamoxifen as adjuvant treatment for early-stage breast cancer: 10-year analysis of the ATAC trial. Lancet Oncol. 2010;11(12): $1135-1141$.

8. Regan MM, Neven P, Giobbie-Hurder A, et al; BIG 1-98 Collaborative Group; International Breast Cancer Study Group (IBCSG). Assessment of letrozole and tamoxifen alone and in sequence for postmenopausal women with steroid hormone receptor-positive breast cancer: the BIG 1-98 randomised clinical trial at $8 \cdot 1$ years median follow-up. Lancet Oncol. 2011;12(12):1101-1108.

9. Regan MM, Price KN, Giobbie-Hurder A, Thürlimann B, Gelber RD; International Breast Cancer Study Group and BIG 1-98 Collaborative Group. Interpreting Breast International Group (BIG) 1-98: a randomized, double-blind, phase III trial comparing letrozole and tamoxifen as adjuvant endocrine therapy for postmenopausal women with hormone receptor-positive, early breast cancer. Breast Cancer Res. 2011;13(3):209.

10. Perez EA, Romond EH, Suman VJ, et al. Four-year follow-up of trastuzumab plus adjuvant chemotherapy for operable human epidermal growth factor receptor 2-positive breast cancer: joint analysis of data from NCCTG N9831 and NSABP B-31. J Clin Oncol. 2011;29(25): 3366-3373.

11. Slamon D, Eiermann W, Robert N, et al; Breast Cancer International Research Group. Adjuvant trastuzumab in HER2-positive breast cancer. N Engl J Med. 2011;365(14):1273-1283.

12. Gonzalez-Angulo AM, Morales-Vasquez F, Hortobagyi GN. Overview of resistance to systemic therapy in patients with breast cancer. $A d v$ Exp Med Biol. 2007;608:1-22.

13. Banga SS, Ozer HL, Park SK, Lee ST. Assignment of PTK7 encoding a receptor protein tyrosine kinase-like molecule to human chromosome $6 \mathrm{p} 21.1->\mathrm{p} 12.2$ by fluorescence in situ hybridization. Cytogenet Cell Genet. 1997;76(1-2):43-44.

14. Jung JW, Ji AR, Lee J, Kim UJ, Lee ST. Organization of the human PTK7 gene encoding a receptor protein tyrosine kinase-like molecule and alternative splicing of its mRNA. Biochim Biophys Acta. 2002;1579(2-3):153-163.

15. Park SK, Lee HS, Lee ST. Characterization of the human full-length PTK7 cDNA encoding a receptor protein tyrosine kinase-like molecule closely related to chick KLG. J Biochem. 1996;119(2):235-239.

16. Lhoumeau AC, Puppo F, Prébet T, Kodjabachian L, Borg JP. PTK7: a cell polarity receptor with multiple facets. Cell Cycle. 2011;10(8): 1233-1236.

17. Lu X, Borchers AG, Jolicoeur C, Rayburn H, Baker JC, TessierLavigne M. PTK7/CCK-4 is a novel regulator of planar cell polarity in vertebrates. Nature. 2004;430(6995):93-98.

18. Peradziryi H, Tolwinski NS, Borchers A. The many roles of PTK7: a versatile regulator of cell-cell communication. Arch Biochem Biophys. 2012;524(1):71-76.

19. Shin WS, Maeng YS, Jung JW, Min JK, Kwon YG, Lee ST. Soluble PTK7 inhibits tube formation, migration, and invasion of endothelial cells and angiogenesis. Biochem Biophys Res Commun. 2008;371(4): 793-798.

20. Endoh H, Tomida S, Yatabe Y, et al. Prognostic model of pulmonary adenocarcinoma by expression profiling of eight genes as determined by quantitative real-time reverse transcriptase polymerase chain reaction. J Clin Oncol. 2004;22(5):811-819. 
21. Gobble RM, Qin LX, Brill ER, et al. Expression profiling of liposarcoma yields a multigene predictor of patient outcome and identifies genes that contribute to liposarcomagenesis. Cancer Res. 2011;71(7): 2697-2705.

22. Lin Y, Zhang LH, Wang XH, et al. PTK7 as a novel marker for favorable gastric cancer patient survival. J Surg Oncol. 2012;106(7):880-886.

23. Mossie K, Jallal B, Alves F, Sures I, Plowman GD, Ullrich A. Colon carcinoma kinase-4 defines a new subclass of the receptor tyrosine kinase family. Oncogene. 1995;11(10):2179-2184.

24. Prebet T, Lhoumeau AC, Arnoulet C, et al. The cell polarity PTK7 receptor acts as a modulator of the chemotherapeutic response in acute myeloid leukemia and impairs clinical outcome. Blood. 2010;116(13):2315-2323.

25. Saha S, Bardelli A, Buckhaults $\mathrm{P}$, et al. A phosphatase associated with metastasis of colorectal cancer. Science. 2001;294(5545): $1343-1346$.
26. Gärtner S, Gunesch A, Knyazeva T, et al. PTK 7 is a transforming gene and prognostic marker for breast cancer and nodal metastasis involvement. PLoS ONE. 2014;9(1):e84472.

27. Wolff AC, Hammond ME, Schwartz JN, et al; American Society of Clinical Oncology; College of American Pathologists. American Society of Clinical Oncology/College of American Pathologists guideline recommendations for human epidermal growth factor receptor 2 testing in breast cancer. J Clin Oncol. 2007;25(1):118-145.

28. Chomczynski P, Sacchi N. Single-step method of RNA isolation by acid guanidinium thiocyanate-phenol-chloroform extraction. Anal Biochem. 1987;162(1):156-159.

29. Meng L, Sefah K, O’Donoghue MB, et al. Silencing of PTK7 in colon cancer cells: caspase-10-dependent apoptosis via mitochondrial pathway. PLoS ONE. 2010;5(11):e14018.

30. Ataseven B, Angerer R, Kates R, et al. PTK7 expression in triplenegative breast cancer. Anticancer Res. 2013;33(9):3759-3763.

\section{Publish your work in this journal}

OncoTargets and Therapy is an international, peer-reviewed, open access journal focusing on the pathological basis of all cancers, potential targets for therapy and treatment protocols employed to improve the management of cancer patients. The journal also focuses on the impact of management programs and new therapeutic agents and protocols on

\section{Dovepress}

patient perspectives such as quality of life, adherence and satisfaction. The manuscript management system is completely online and includes a very quick and fair peer-review system, which is all easy to use. Visit http://www.dovepress.com/testimonials.php to read real quotes from published authors.

Submit your manuscript here: http://www.dovepress.com/oncotargets-and-therapy-journal 